\title{
Cerebral hydatid disease in Britain
}

\author{
MILNE ANDERSON, EDWIN R. BICKERSTAFF, AND J. G. HAMILTON \\ From the Midland Centre for Neurosurgery and Neurology, Holly Lane, \\ Smethwick, West Midlands
}

SYNOPSIS Two cases of cerebral hydatid disease are described. This condition, acquired by Britons in Britain, is extremely rare as only two similar cases have been reported before. Details of clinical presentation, investigation_and treatment are described.

Within the Isles of Britain clinical human infestation with the parasite Echinococcus granulosus is rare. Such infestation usually derives from dogs in whose intestines the adult Taenia live. Eggs are deposited in the faeces and ingested by sheep who harbour the parasite through the cystic stage of its life cycle. Man becomes infected by contact with dogs, usually those who work sheep, and children are particularly susceptible by fondling an animal whose coat contains eggs. Once ingested, the embryo passes into the gut, penetrates the intestinal wall, usually the duodenum, and travels via the portal system to liver, lung, and other viscera where hydatid cysts form. This explains the localization of cysts in different organs- $65 \%$ in liver, $20 \%$ in lung, and the remainder scattered elsewhere. Intracranial localization of a hydatid is exceedingly rare and accounts for only $1-2 \%$ of cases of hydatid infestation (Langmaid and Rogers, 1940; Robinson, 1960; Arana-Ineguez, 1973). The recent admission of a patient with cerebral hydatid to the Midland Centre for Neurosurgery and Neurology (M.C.N.N.) stimulated search for further similar cases. One other has been treated at this centre and a survey of the literature shows that only two cases of cerebral hydatid disease occurring in Britons and acquired in this county have been documented (Langmaid and Rogers, 1940; Rhodes, 1954). Provided the diagnosis be considered, investigation and treatment can be undertaken in such a way as to minimize the risk of dissemination of the disease

(Accepted 9 June 1975.) and ensure its cure. To this end, details of our two cases are presented and clinical and diagnostic pointers emphasized.

CASE 1

A boy of 7 years of age who had never been ill before developed headache and vomiting four days before admission to hospital in Hereford. The only abnormalities on examination were mild neck stiffness and pyrexia. Examination of lumbar cerebrospinal fluid (CSF) revealed lymphocytosis of 145 per $\mathrm{mm}^{3}$, protein content $0.92 \mathrm{~g} / \mathrm{l}$, sugar $4.27 \mathrm{mmol} / 1$ (77 $\mathrm{mg} / \mathrm{dl})$, and chloride $93.2 \mathrm{mmol} / \mathrm{l}(545 \mathrm{mg} / \mathrm{dl})$. A tentative diagnosis of tuberculous meningitis was made and treatment given with PAS, INAH, streptomycin, and pyridoxine. Headache and vomiting continued: he developed papilloedema, generalized lymphadenopathy, and a diffuse papular rash. After 10 days the rash, pyrexia, and meningism subsided but optic disc swelling increased and he was transferred to M.C.N.N. for further investigation.

Examination showed a fully conscious child with bilateral papilloedema and no other abnormality. There was no meningism.

Haematological investigations showed: haemoglobin $12.6 \mathrm{~g} / \mathrm{dl}$, white cell count $9000 / \mathrm{mm}^{3}$ of which $54 \%$ were neutrophils, $29 \%$ lymphocytes, $10 \%$ eosinophils, and $7 \%$ monocytes. Erythrocyte sedimentation rate was $17 \mathrm{~mm}$ in one hour. Electroencephalogram showed delta activity in the left anterior quadrant. Radiographs of the skull showed mild suture diastasis and of chest were normal. A lumbar pneumoencephalogram demonstrated displacement of the lateral ventricles to the right by a posteriorly situated tumour. Cerebrospinal fluid was now normal. Left carotid arteriography showed the 


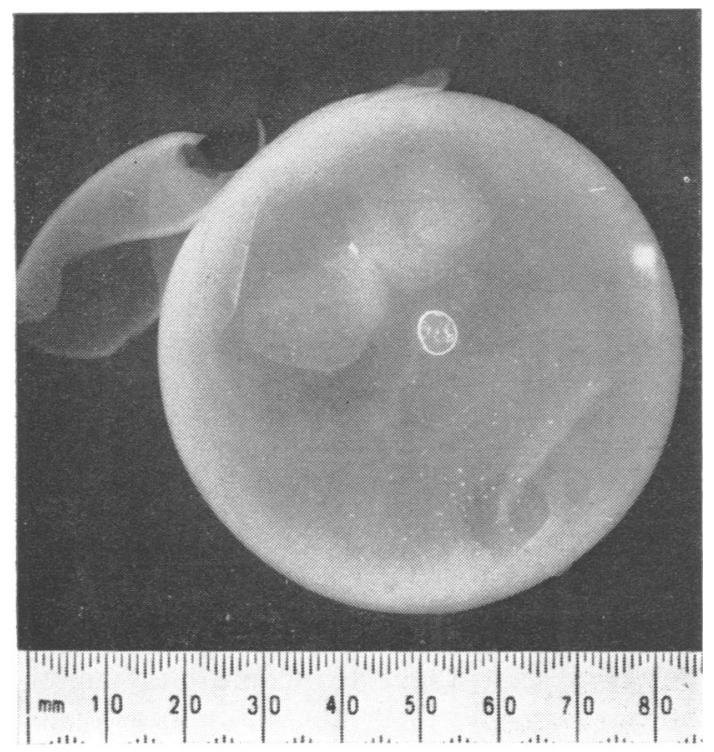

FIG. 1 Case 1. Hydatid cyst. lesion to be avascular, intrinsic, and in the parietal area.

Exploration by J. G. Hamilton was performed through a left parietal craniotomy. An encapsulated mass was encountered $1.5 \mathrm{~cm}$ below the cortex, pierced, and fluid aspirated (Fig. 1). A thin inner membrane was found to contain glistening particles in regular rows. Histology confirmed that they were hydatid scolices. The inner capsule was delivered intact and the cavity washed with saline and ether. After this, the patient made an uninterrupted recovery and, when reviewed 18 months later, the only abnormal sign was minimal postural deficit of the right arm. Both his mother and father were found to have cystic opacities in the lung fields on chest radiography which were thought to be hydatids.

\section{CASE 2}

One month before admission to M.C.N.N. a boy aged 14 years noticed that if he turned his head quickly vision of both eyes would blur for a few seconds. Two weeks later he experienced severe

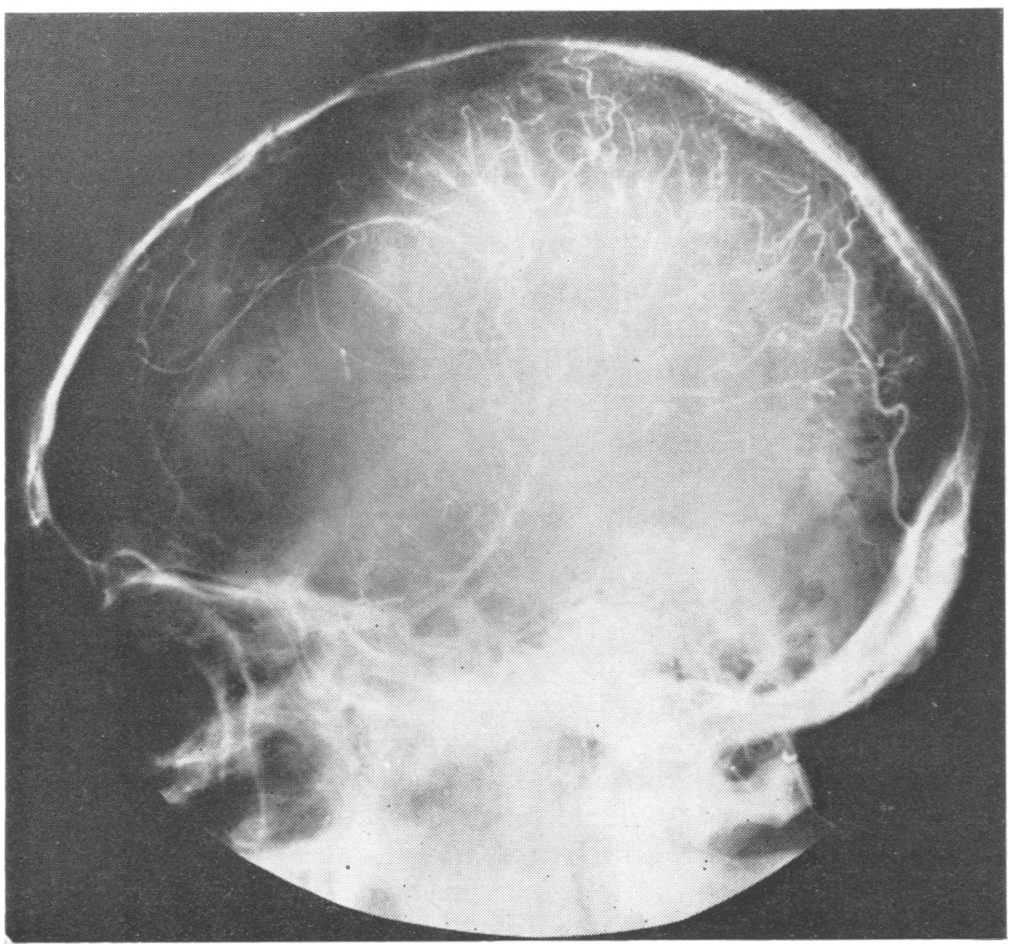

FIG. 2 Case 2. Left carotid arteriogram showing $10 \mathrm{~cm}$ diameter avascular frontal lesion, with circumferential vessels. 
occipital headache which would last for 10 minutes and occur two or three times each day. His general practitioner noted papilloedema, referred him to hospital in Hereford where optic disc swelling was confirmed and urgent transfer to M.C.N.N. was requested. There was no history of note before. It is of interest that during the course of his illness two weeks before admission to hospital he won the senior discus event at his school sports with a record throw!

Examination showed a big strong boy with florid bilateral papilloedema and no other abnormality.

Results of investigations were haemoglobin 14.9 $\mathrm{g} / \mathrm{dl}$, white cell count $9000 / \mathrm{mm}^{3}, 73 \%$ neutrophils, $15 \%$ lymphocytes, $6 \%$ eosinophils, and $6 \%$ monocytes. Erythrocyte sedimentation rate was $26 \mathrm{~mm}$ in one hour. Blood urea, sugar, electrolytes, liver function tests, and Wassermann reaction were normal. Chest radiography was normal. Radiographs of the skull showed erosion of the sella and slight suture diastasis. An electroencephalogram showed bilateral slow wave activity. Technetium isotope brain scan showed that the midline structures were displaced to the right and there was a large area of diminished uptake in the left frontal area. A left carotid arteriogram demonstrated a huge avascular frontal lesion, $10 \mathrm{~cm}$ in diameter (Fig. 2). Later, a liver scan was normal, Casoni test was negative, and hydatid complement fixation test positive at a titre of $1 / 2$, which is a very low figure.

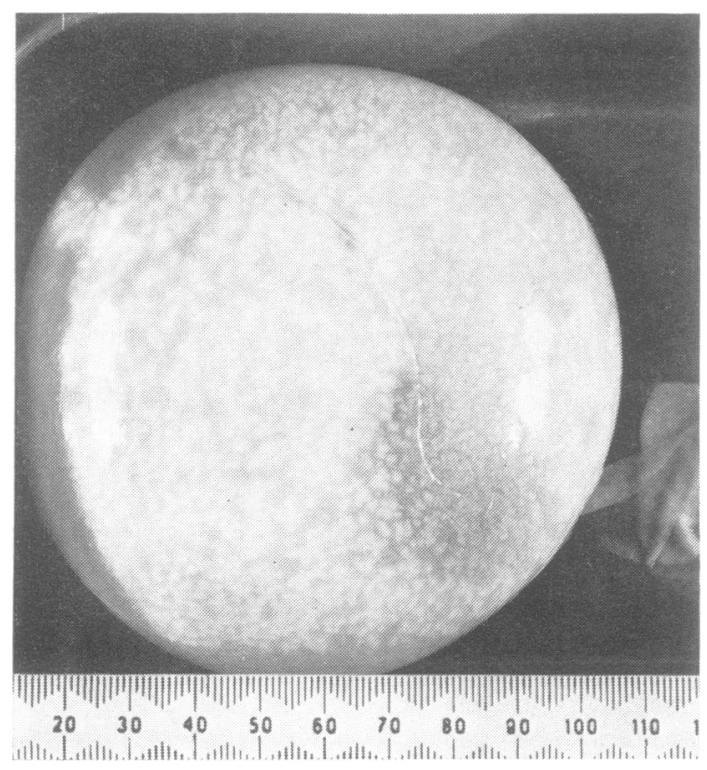

FIG. 3 Case 2. Hydatid cyst.
A surgical opinion from J. G. Hamilton suggested that the lesion might be a hydatid cyst and craniotomy was advised. Through a left frontal approach a huge cyst was encountered immediately beneath the cerebral cortex. By the ingenious method described by Arana-Ineguez and San Julian (1955), saline was injected between the cyst and underlying brain, so extruding the cyst which was delivered to the surface intact and removed (Fig. 3). Histology confirmed that it was a hydatid cyst. The boy made a complete and uninterrupted recovery.

\section{DISCUSSION}

Those two cases are of interest on several counts. Reports of hydatid disease are uncommon in Britain and cerebral cysts rare among these. Figures of the incidence of hydatid disease are difficult to come by. Forbes and Cooke (1963) considered that about 15 people die from the disease every year in Britain and approximately 90 new cases are recognized annually, but they do not indicate their sources. Bradstreet (1969) was able to gather material from 129 surgically proven cases in a 10 year period and only one of these involved brain. There are several reports of hydatid disease in the British literature but few involve brain. Of these, most concern cases occurring overseas or in whom the infection has been contracted abroad (Nedwill, 1898; Fleming and Bury, 1919; Phillips, 1948; Robinson, 1960; King and Couch, 1961). We have been able to find reports of only two cases of cerebral hydatid in Britons (Langmaid and Rogers, 1940; and, Rhodes, 1954). The case of Caley (1903) is probably a third but details are sparse and that of Dagleish (1831-2) is most likely a cystic tumour. Langmaid and Rogers (1940) quote instances of two other cases at Cardiff but were unable to find their records and they knew of another case by personal communication from the London Hospital but no details were given.

Cerebral hydatid is a disease of children in the main, most cases occurring in the first or second decade (Phillips, 1948; Robinson, 1960). There is no pathognomonic symptom or sign, yet a pattern may emerge which makes the diagnosis likely - once it has been thought of. Intracranial hypertension with headache and papilloedema is invariable yet the child appears in good general health. There is seldom a well-defined focal syndrome, perhaps because the cyst grows slowly without directly involving adjacent brain. 
Schroeder's 'four points' are useful guidelines -a child from a rural area, in good general condition, with marked intracranial hypertension yet with ill-defined focal signs (Schroeder, 1941 quoted by Arana-Ineguez, 1973).

Both our cases satisfy these criteria. The first had a meningitic illness which rapidly subsided and has not been adequately explained, although it is possible that the paraventricular location of the cyst incited meningeal reaction. The second patient remained exceedingly fit throughout and would not have sought medical advice but for visual obscuration consequent upon papilloedema.

Skull radiographs demonstrated early suture diastasis in the first case and moderate changes in the second. Isotope brain scan was undertaken in the second case and was abnormal with displacement of midline structures and lack of uptake in the area of the cyst, features which may be seen with any large cystic lesion and have been remarked in brain hydatids by Arana-Ineguez (1973).

Arteriography is the investigation of choice for localization of the lesion, although it would be interesting to see the results of computerized axial tomography in such cases. Angiographic features are those of a large avascular intrinsic lesion, no abnormal circulation throughout, and circumferential vessels demonstrating its extent. Air studies either by ventriculography or lumbar encephalography are contraindicated as rupture of the cyst may occur with dissemination of the disease inside the cranium. In our first case basal arachnoiditis from tuberculous meningitis was suspected and the demonstration of a space occupying lesion was unexpected.

Complete surgical removal without rupture of the cyst is the treatment of choice and the method described by San Julian and Arana-Ineguez (1954) and Arana-Ineguez and San Julian (1955) is a model of simplicity and completely effective. Tapping of the cyst or injection of formalin should not be undertaken. Both our patients have made complete recoveries, although the cyst was tapped in the first.

The value of antibody investigations is difficult to estimate. In the present clinical context - that of a child with raised intracranial pressure and papilloedema-there is not time to await the result of complement fixing, immuno- electrophoretic, haemagglutination, or immunofluorescein studies. The results of these tests may be disappointing in cerebral hydatid as may the Casoni reaction. In our cases, eosinophilia of peripheral blood might have given a diagnostic pointer. Neither had evidence of hepatic or pulmonary hydatid disease. Hydatid brain cysts are thought to be primary cysts, so that evidence of infestation elsewhere in the body is unusual (Phillips, 1948; Arana-Inequez and San Julian, 1955). Hence the excellent prognosis if the cysts can be removed intact.

In our two cases it is likely that the infestation came from dogs, as both boys often played with animals who tended sheep. They lived in sheep rearing areas within 30 miles of each other near the Welsh border, one in Monmouthshire, the other in Radnorshire. The case of Langmaid and Rogers (1940) was seen in Cardiff, and Rhodes (1954) reported from Bridgnorth in Shropshire. Throughout the world where sheep are reared there are reservoirs of infection-in Australia and New Zealand (Robinson, 1960), in Uruguay (Arana-Ineguez and San Julian, 1955), in Rumania (Arseni and Samitica, 1957), and in Iraq (Marki, 1970). In Britain the sheep rearing areas of Wales, Hereford, and Monmouth are the main reservoirs (Wolfe, 1943; Bradstreet, 1969).

In Britain, brain infestation with other forms of parasite is unlikely to cause diagnostic confusion. A coenurus from the dog tapeworm Multiceps multiceps may form a large cerebral cyst in many respects like a hydatid, but this has not been described in Great Britain before. Cysticerci may form supratentorial cysts but these are smaller, there is frequently a history of epilepsy, and the infestation has been acquired abroad in Eastern Europe or Asia. The racemose form and involvement of the posterior fossa have been described by Bickerstaff et al. (1952) and Bickerstaff et al. (1956) and are quite different from hydatids.

Although extremely rare, these two cases demonstrate that cerebral hydatid disease may be contracted in Britain by native Britons living in rural areas where sheep and dogs are infected by Echinococcus granulosus. The diagnosis should be considered in any young adult presenting with papilloedema and other stigmata of raised intracranial pressure, ill-defined focal signs, general wellbeing, and from a rural area, since cure is 
possible if the correct investigations are undertaken and removal of the cyst without rupture carried out.

Thanks are due to the Department of Pathology, MCNN, for photographs of the cysts and to Miss Margaret Leddington for typing the manuscript.

\section{REFERENCES}

Arani-Ineguez, R., and San-Julian, J. (1955). Hydatid cysts of the brain. Journal of Neurosurgery, 12, 323-335.

Arana-Ineguez, R. (1973). Hydatid echinococcosis of the nervous system. In Tropical Neurology, pp. 408-417. Edited by J. D. Spillane. Oxford University Press: London.

Arseni, C., and Samitica, D. (1957). Cranial and cerebral hydatid disease. Acta Psychiatrica et Neurologica Scandinavia, 32, 389-398.

Bickerstaff, E. R., Cloake, P. C. P., Hughes, B., and Smith, W. T. (1952). The racemose form of cerebral cysticercosis. Brain, 75, 1-18.

Bickerstaff, E. R., Small, J. M., and Woolf, A. L. (1956). Cysticercosis of the posterior fossa. Brain, 79, 622-633.

Bradstreet, C. M. P. (1969). A study of two immunological tests in the diagnosis and prognosis of hydatid disease. Journal of Medical Microbiology, 2, 419-432.

Caley, H. A. (1903). Hydatid of the brain-cyst wall. Brain, 26, 613.
Dagleish, G. (1831-32). Case of hydatid found in the fourth ventricle of the brain. Lancet, $2,168$.

Fleming, N. B. B., and Bury, G. W. (1919). A case of primary hydatid disease of the brain with interesting eye symptoms. Lancet, 2, 1186-1189.

Forbes, L. S., and Cook, B. R. (1963). Hydatid disease in the United Kingdom. Transactions of the Roval Society of Trupical Medicine and Hygiene, 57, 5.

King, T. T., and Couch, R. S. C. (1961). The diagnosis of cerebral hydatid disease. Clinical Radiology, 12, 190-193.

Langmaid, C., and Rogers, L. (1940). Intracranial hydatids. Brain, 63, 184-190.

Marki, H. (1970). Some rare cases of hydatid disease. British Journal of Clinical Practice, 24, 125-129.

Nedwill, C. (1898). Five cases of abdominal surgery and a case of hydatid tumour of the brain. Lancet, 1, 1466-1467.

Phillips, G. (1948). Primary cerebral hydatid cysts. Journal of Neurology, Neurosurgery, and Psychiatry, 11, 44-52.

Rhodes, P. L. (1954). An unusual case of hydatid cyst of the brain. British Medical Journal, 2, 739.

Robinson, R. G. (1960). Hydatid disease affecting the nervous system. Annals of the Royal College of Surgeons of England, 26, 145-156.

San-Julian, J., and Arana-Ineguez, R. (1954). Nevou metodo para la extirpacion del quiste hidatico cerebral. Boletin de la Sociedad de Cirugia del Uruguay, 25, 722-728.

Schroeder, A. H. (1941). Diagnostico del quiste hidatico cerebral y su tratamiento. Anales del Instituto de Neurologia, Montevideo, 3, 11-38.

Wolfe, H. R. I. (1943). Hydatid disease in Wales. Lancet, 1 , 795 . 